CLINICAL STUDY

\title{
Phenotype and HFE genotype in a population with abnormal iron markers recruited from an Endocrinology Department
}

\author{
Marie-Christine Vantyghem ${ }^{1}$, Isabelle Fajardy ${ }^{2}$, Florence Dhondt ${ }^{1}$, Caroline Girardot $^{1}$, Michèle D’Herbomez ${ }^{3}$, \\ Pierre-Marie Danze ${ }^{2}$, Jean Rousseaux ${ }^{2}$ and Jean-Louis Wemeau ${ }^{3}$ \\ ${ }^{1}$ Endocrinology and Metabolism Department, ${ }^{2}$ Biochemistry Department and ${ }^{3}$ Nuclear Medicine Laboratory, Lille University Hospital, 6 , Rue du Pr \\ Laguesse, 59037 Lille cedex, France
}

(Correspondence should be addressed to M-C Vantyghem; Email: mc-vantyghem@chru-lille.fr)

\begin{abstract}
Objective: The aim of this study was to describe HFE genotype in a population of patients with altered iron markers recruited in an Endocrinology Department and to define the possible phenotypegenotype relationships.

Methods: A total of 156 patients with high serum ferritin concentrations ( $>300 \mathrm{ng} / \mathrm{ml}$ ) or transferrin saturation ( $>45 \%$ ) (I group), and a control group of 106 healthy subjects (C group) underwent HFE genotyping (classical $\mathrm{C} 282 \mathrm{Y}$ and H63D mutations). We also examined the main genetic features of subgroups in I according to the presence (D) or the absence (ND) of diabetes.

Results: (1) The genotypes were significantly different in the I and $\mathrm{C}$ groups $(P<0.001)$, with an increased frequency of major $282 \mathrm{Y}$ allele in the I group ( $35 \%$ vs $7.5 \%)$, but not of minor $63 \mathrm{D}$ allele (17 vs $18.5 \%)$. (2) The genotype of D and ND groups also differed $(P<0.0001)$, with a lower frequency of C282 heterozygosity $(P<0.0001)$ in the D group, and a higher prevalence of H63D heterozygosity in the D vs ND groups $(P<0.01)$. (3) The phenotypic comparison of $\mathrm{D}$ and ND groups also showed a higher mean body mass index, age, and serum ferritin concentration, as well as an increased proportion of males with increased liver enzymes in the D group.

Conclusion: This population harboring abnormal iron markers had a different HFE genotype and a higher $282 Y$ allele frequency than the control population. This suggests that blood iron markers could be checked in etiological investigations of metabolic disturbances to identify patients who should undergo genotyping, since approximately $20 \%$ were diagnosed with C282Y homozygosity.
\end{abstract}

European Journal of Endocrinology 154 835-841

\section{Introduction}

Hereditary hemochromatosis $(\mathrm{HH})$ is an iron-storage disease with a phenotype characterized by biochemical changes reflecting abnormal iron homeostasis (e.g. changes in transferrin saturation (TS) and serum ferritin concentrations) and altered total-body iron burden. The symptoms of $\mathrm{HH}$ include cirrhosis of the liver, diabetes, hypogonadism, hypermelanotic pigmentation of the skin, and heart failure. Primary hepatocellular carcinoma, complicating cirrhosis, is responsible for about one-third of deaths in affected homozygotes. Iron overload increases insulin resistance, accentuating the risks for cardiovascular complications (1). The HFE gene was cloned in 1996, and homozygosity for the $845 \mathrm{G}-\mathrm{A}$ (C282Y) mutation has been found in over $80 \%$ of patients diagnosed with iron overload due to HH. Compound heterozygotes for the
C282Y and $187 \mathrm{C}-\mathrm{G}$ (H63D) mutations are also overrepresented in the $\mathrm{HH}$ population. This disease is one of the most common genetic disorders in northern Europe: about 5 in every 1000 northern Europeans are homozygous for the $C 282 Y$ mutation. Because the homozygous genotype for hemochromatosis is common, and because iron overload is readily treated by phlebotomy, the mutation has been regarded as ideally suited for population screening. However, although most patients of European origin who have been clinically diagnosed with $\mathrm{HH}$ have either the C282Y/ $\mathrm{C} 282 \mathrm{Y}$ or the $\mathrm{C} 282 \mathrm{Y} / \mathrm{H} 63 \mathrm{D}$ genotype, there is scant and conflicting information about type and number of people in the general population with this genotype and its clinical manifestations. Therefore, the relevance of systematically studying iron metabolism in the general population is still debated, since the penetrance of HFE mutations is low (2-4). Moreover, recent studies have 
emphasized the role of ferritin as a marker of insulin resistance (5). In western countries, most health authorities recommend an early identification of mutated patients based on clinical symptoms and iron biological parameters, coupled with a family inquiry. The issue is that the clinical phenotype of $\mathrm{HH}$ is very heterogeneous and phenotype-genotype correlation is not well known because of the recent availability of genetic tools. Therefore, the aim of this study was to describe the HFE genotype in a population of patients recruited in an Endocrinology Department with abnormal iron markers and to define the possible phenotype-genotype relationships.

\section{Research design and methods}

\section{Patients}

Patients with abnormal iron markers (I group). One hundred and fifty six subjects, recruited in the Endocrinology and Metabolism Department of Lille University Hospital, corresponding to about 5\% of our total recruitment, were included for abnormal iron levels (serum ferritin $>300 \mathrm{ng} / \mathrm{ml}$ or $\mathrm{TS}>45 \%$ ). Iron metabolism investigations were performed either because of general symptoms (fatigue, weight loss, arthralgia), diabetes, hepatomegaly, disturbed liver enzymes, or for hypogonadism. Clinical, biochemical and genotype information was collected before treatment. Informed consent was obtained from all the patients before genotype sampling. The population was divided into two groups according to their diabetic status as defined by the WHO criteria: Group D included 81 diabetic patients and group ND 75 non-diabetic subjects. We also compared 3 subgroups of patients divided according to their level of serum ferritin level $(n=148):<500 \mathrm{ng} / \mathrm{ml}(n=73),>500$ but $<1000$ $(n=34),>1000 \quad(n=41)$. Finally, we compared 4 subgroups of patients divided according to their HFE genotype: $C 282 Y$ homozygote $(n=33), C 282 Y$ heterozygote $(n=34)$, H63D homo- and heterozygote, double heterozygote $(n=50)$, no mutation $(n=39)$.

Control group (C group). The C group included 106 healthy Caucasian subjects, without family history of diabetes or iron overload.

\section{Methods}

Clinical data. Clinical data were registered as follows: gender, age, ethnic origin, Body Mass Index (BMI), alcohol intake, arthralgia, melanodermy, hepatomegaly, cardiopathy, and diabetes defined as at least two fasting blood glucose levels above $1.25 \mathrm{~g} / \mathrm{l}(7 \mathrm{mmol} / \mathrm{l})$, or one random blood glucose level above $2 \mathrm{~g} / \mathrm{l}(11 \mathrm{mmol} / \mathrm{l})$ or current treatment for diabetes (insulin or oral antidiabetic drugs). Most of these patients had type 2 diabetes with positive $\mathrm{C}$ peptide.

Biological data. Sampling times. Blood samples for iron parameters were collected from fasting patients.

Routine measurements. Glycemia (Glc; mmol/l), plasma alkaline phosphatases (UI/l), gamma-glutamyl and amino-transferases (UI/l) were measured with routine laboratory methods. HbA1c was assessed by means of high-performance liquid chromatography.

Measurement of serum iron, transferrin and ferritin. Serum iron levels were measured using a standard colorimetric method, and serum transferrin levels were determined by rate immunoturbidimetry on an automated analyzer. Serum TS values were calculated as follows: ((serum iron $/ 2) \times$ serum transferrin $) \times \times 100$. Serum ferritin levels were measured by chemiluminescence immunoassay (Immulite 2000, DPC, France).

Identification of the $\mathrm{C} 282 \mathrm{Y}$ and $\mathrm{H} 63 \mathrm{D}$ mutations in the HFE Gene. Genotyping consisted of analyzing HFE genotypes. DNA was extracted from whole blood samples. The two HFE mutations were detected with PCR assays followed by restriction-enzyme digestion with Rsa1 for the $C 282 Y$ mutation and Bcl1 for the H63D mutation.

Statistical analysis. Results were expressed as means \pm S.D. A Student $t$ test was used to compare means between two groups with $n>30$. Group-wise comparisons were made using analysis of variance (ANOVA) followed by the Wilcoxon test or KruskallWallis test. Least squares analysis (Pearson $r$ value) was used to identify correlation in the overall population $(n=156)$. Comparison of percentages was performed by the chi-square test with Yate's correction. The level of significance was $P<0.05$.

For allelic comparisons, $P$ values were corrected $(P c)$ by the number of tests. Odd ratios were calculated by the method of Woolf (6) and Haldane (7). The power of the study was $82 \%$ for a theoretical sample of 148 persons with an $\alpha$ risk of 0.01 .

\section{Results}

\section{Characteristics of the I Group}

Clinical characteristics, serum liver enzymes, iron markers levels of the entire population are shown in Table 1, and genetic results in Table 2. 
Table 1 Main clinical characteristics of the whole group of patients with abnormal iron markers and comparison of diabetic and non-diabetic subgroups.

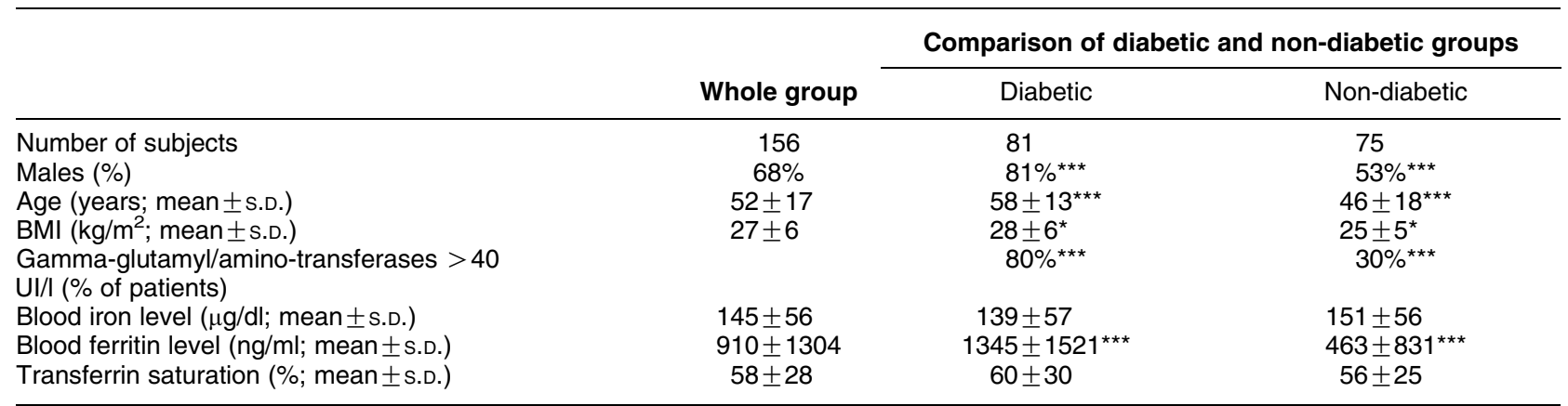

${ }^{*} P<0.05 ;{ }^{* *} P<0.01 ;{ }^{* \star *} P<0.001$.

Ethnic origin. 96.2\% of patients were Caucasian. The non-Caucasian patients were native of North Africa. Among them was one homozygote for H63D mutation.

Clinical symptoms. $11 \%$ of patients were melanodermic. $51 \%$ were diabetic with mean glycated hemoglobin of $8.7 \pm 2.8 \%(N<6.5 \%) ; 24 \%$ admitted to excessive alcohol intake $(>30 \mathrm{~g} /$ day $) ; 26 \%$ had hepatomegaly; $10 \%$ spontaneously complained of arthralgia; and 10\% suffered from heart disease.

\section{Group correlation}

Iron markers did not correlate with any of the clinical or biological parameters (age, BMI, aminotransferase, glycemia) in the overall population.

\section{Group comparison (Tables 1 and 2)}

Comparison of the genotype and allelic frequency (Table 2) in the I and $C$ groups. Genotypes differed significantly in the I and $C$ groups $\left(\chi^{2} ; P<0.001\right)$. The frequency of major allele $C 282 Y(35 \%$ vs $7.5 \%)$ was significantly higher in the I group than in the $\mathrm{C}$ group. Minor allele H63D (17 vs $18.5 \%$ ) did not differ between the two groups.

Diabetic and non-diabetic groups. The genotype of $D$ and ND groups also differed significantly from the C group with an increased frequency of mutated major allele $282 Y$, but not of minor allele $63 \mathrm{D}$ (17\% vs $18.3 \%$ ). The genotype of the D group also differed from the ND group $(P<0.01)$ for both mutated alleles, with a lower frequency of the mutated major allele $(P<0.0001)$ but a higher frequency of the minor allele $(P<0.01)$ in the D group. The $D$ and ND groups also differed significantly for age $(P<0.001)$, BMI $(P<0.05)$, ferritin $(P<0.001)$, gender $(P<0.001)$, increased levels of amino-transferases or gamma-glutamyl transferase $(P<0.001)$ (Table 1), C282Y heterozygosity $(P<0.001)$, and H63D heterozygosity $(P<0.05)\left(\chi^{2}\right)$. We did not, however, find any statistical difference between groups for mean TS, frequency of C282Y, H63D homozygosity and composite heterozygosity or lack of HFE mutation.

Table 2 Genetic profile of the I (abnormal iron parameters), diabetic (D), non-diabetic (ND), and control (C) groups.

\begin{tabular}{lcccc}
\hline Genotypes & C & I & D & ND \\
\hline Number of subjects & 106 & 156 & 81 & 75 \\
Homozygosity 282Y & $0 \%$ & $33(21 \%)$ & $13(16 \%)$ & $20(26.6 \%)$ \\
Composite heterozygosity & $2(1.8 \%)$ & $10(6.4 \%)$ & $5(6.2 \%)$ & $5(6.7 \%)$ \\
Heterozygosity 282Y & $14(13.2 \%)$ & $34(21 \%)$ & $11(13.6 \%)$ & $23(30.6 \%)$ \\
Homozygosity 63D & $7(6.6 \%)$ & $5(3.2 \%)$ & $4(5 \%)$ & $1(1.3 \%)$ \\
Heterozygosity 63D & $23(21.6 \%)$ & $33(21 \%)$ & $23(28.4 \%)$ & $10(13 \%)$ \\
No mutation & $60(5 \%)$ & $41(26 \%)$ & $25(31 \%)$ & $16(21 \%)$ \\
Alleles & & & & 162 \\
$2 n$ number of subjects & 212 & 312 & $42(26 \%)$ & 150 \\
$282 Y$ & $16(7.5 \%)$ & $110(35 \%)$ & $120(74 \%)$ & $68(45 \%)$ \\
$282 C$ & $196(92.5 \%)$ & $202(65 \%)$ & $36(22 \%)$ & $17(11 \%)$ \\
$63 D$ & $39(18.3 \%)$ & $53(17 \%)$ & $126(78 \%)$ & $133(89 \%)$ \\
$63 H$ & $173(81.7 \%)$ & $259(83 \%)$ & \\
\hline
\end{tabular}

Genotype: Whole I vs C: $(P<0.0001)$; D vs ND $(P<0.01)$; D vs C $(P<0.0001)$ ND vs C $(P<0.0001)$ Alleles: Whole I vs C: $282 Y(P<0.0001,0 R=13) ; 63 D$ (NS); D vs C: $282 Y(P<0.0001, \mathrm{OR}=6) ; 63 D(\mathrm{NS}) ; \mathrm{ND}$ vs C: $282 Y(P<0.0001, \mathrm{OR}=54) ; 63 D(\mathrm{NS}) ; \mathrm{D}$ vs ND: $282 Y(P<0.0001, \mathrm{OR}=0.11) ; 63 D(P<0.01$, $\mathrm{OR}=2.73)$. OR, odds ratio; NS, not significant. 
Comparison of subgroups according to ferritin level $(<500,500-1000$, and $>1000 \mu \mathrm{g} / \mathrm{dl})$ (Table 3). The 3 subgroups differed significantly for age (ANOVA; $P<0.001$ ), gender, diabetes, increased liver enzyme $\left(\chi^{2} ; P<0.001\right)$, and $C 282 Y$ heterozygosity frequency $\left(\chi^{2} ; P<0.01\right)$. There was no difference, however, for BMI, arthralgia cardiopathy, or frequency of other genotypes. Mean age was also significantly lower (Student test) in subgroup $<500$ compared to the other 2 subgroups $(P<0.001)$ : younger patients had lower ferritin levels. The frequency of male gender, diabetes $(P<0.01)$, and liver enzymes levels $>40 \mathrm{UI} / \mathrm{l}$ $(P<0.01)$ was higher in subgroup $>1000$ than in the other 2 subgroups. C282Y heterozygosity was more frequent in group $<500$ than in the 2 other subgroups.

Comparison of groups according to HFE genotype (Table 4). Statistical differences were found among the four groups as regards means of serum iron level, TS $(P<0.001$ for both), and blood ferritin level $(P<0.01)$ (ANOVA), as well as diabetes, and hepatomegaly frequency $(P<0.01)$, melanodermy $(P<0.05)$, and arthralgia frequency $(P<0.001)\left(\chi^{2}\right)$. There was no significant difference between the four groups as regards age, mean BMI, gender, alcohol intake, cardiopathy, or increased liver enzyme frequency. Details of the comparison between subgroups two by two are given in Table 3. The C282 homozygote genotype was mainly characterized by hepatomegaly, arthralgia and melanodermy. Diabetes was found in about 40 cases, with a frequency nearly similar to the group $\mathrm{C} 282 \mathrm{Y}$ heterozygosity. The highest frequency of diabetes was found in groups "H63D" and "no mutation".

\section{Discussion}

The profile of patients with abnormal iron markers recruited in an endocrinological environment is not well known because of the clinical heterogeneity of $\mathrm{HH}$ and the recent availability of genetic tools. Our aim was definitely not to determine the frequency of diabetes in $\mathrm{HH}$, but rather to describe the HFE genotype in a population of patients with abnormal iron markers recruited in an Endocrinology Department to determine the yield of HFE genotyping, especially according to diabetic phenotype.

First, we compared a control group and the group with abnormal iron parameters. This last group was recruited mainly on metabolic or endocrinological disturbances and included liver burden only in a quarter of cases, usually associated with another non-hepatological symptom. Despite peculiar recruitment, the genotype and allelic frequency of $\mathrm{C}$ and I groups were different, with an increased frequency of major $\mathrm{C} 282 \mathrm{Y}$ in the I group, in accordance with the already known role of $C 282 Y$ HFE mutation in iron metabolism (8). This finding was also demonstrated in I subgroups according to the presence (D) or the absence (ND) of diabetes. These results emphasize the fact that iron marker assessment is a useful tool in an endocrinological recruitment.

The second point was to determine the genotype in $\mathrm{D}$ and ND groups. Interestingly, the D group showed a lower frequency of $C 282 Y$ homozygosity and

Table 3 Comparison of subgroups according to blood ferritin level.

\begin{tabular}{|c|c|c|c|c|}
\hline $\begin{array}{l}\text { Ferritin ( } \mu \mathrm{g} \text { per } 100 \mathrm{ml} \text { ) } \\
\text { Number of subjects }\end{array}$ & $\begin{array}{c}\text { Low }<500 \\
73\end{array}$ & $\begin{array}{c}\text { Mild } 500 \text { to } 1000 \\
34\end{array}$ & $\underset{41}{\text { High }}>1000$ & $\begin{array}{c}{ }^{\star \star} P \\
{ }^{* \star *} P\end{array}$ \\
\hline Age (year) & $46 \pm 19$ & $59 \pm 14$ & $59 \pm 12$ & $\begin{array}{l}\text { ANOVA }{ }^{\star \star *} \\
\text { Low/Mild }^{\star \star \star} \\
\text { Low/High }\end{array}$ \\
\hline $\begin{array}{l}\text { Gender }(\% \text { male }) \\
\text { BMl }\left(\mathrm{kg} / \mathrm{m}^{2}\right)\end{array}$ & $\begin{array}{l}54.8 \\
26.1 \pm 6.7\end{array}$ & $\begin{array}{l}76.5 \\
28.6 \pm 5.4\end{array}$ & $\begin{array}{l}90.2 \\
26.8 \pm 5.3\end{array}$ & $\begin{array}{l}\chi^{2 * * *} \\
\text { NS }\end{array}$ \\
\hline Diabetes (\%) & $28.8^{-1}$ & 61.8 & $80.5^{--1}$ & $\begin{array}{l}\chi^{2 \star \star \star} \\
\text { Low/Mild**} \\
\text { Mild/High }\end{array}$ \\
\hline Arthralgia (\%) & 11.4 & 8.8 & 12.2 & NS \\
\hline Cardiopathy (\%) & 8.6 & 5.9 & 17.1 & NS \\
\hline Liver enzymes $>40 \mathrm{UI} / \mathrm{I}(\%)$ & 35.6 & 67.6 & 82.8 & $\begin{array}{l}\chi^{2 \star \star *} \\
\text { Low/Mild }^{\star *} \\
\text { Mild/High }\end{array}$ \\
\hline C282 homozygosity & 17.8 & 20.6 & 31.7 & NS \\
\hline $\mathrm{C} 282 Y$ heterozygosity & 35.6 & 8.8 & 12.2 & $\begin{array}{l}\chi^{2 * *} \\
\text { Low/Mild }^{\star *} \\
\text { Mild/High }\end{array}$ \\
\hline Composite heterozygosity & 4.1 & 14.7 & 4.9 & NS \\
\hline H63D homozygosity & 2.7 & 5.9 & 2.4 & NS \\
\hline H63D heterozygosity & 15.1 & 26.5 & 29.3 & NS \\
\hline No mutation & 26 & 23.5 & 19.5 & NS \\
\hline
\end{tabular}


Table 4 Comparison of subgroups according to genotype.

\begin{tabular}{|c|c|c|c|c|c|}
\hline Genotype & $\begin{array}{c}\text { C282Y } \\
\text { homozygosity }\end{array}$ & $\begin{array}{c}\text { C282Y } \\
\text { heterozygosity }\end{array}$ & $\begin{array}{l}\text { Composite, } \\
\text { H63D homo- } \\
\text { /heterozygosity }\end{array}$ & No mutation & \\
\hline Gender (\% male) & 69.7 & 55.8 & 72 & 71.8 & NS \\
\hline Age (years) & $54 \pm 18$ & $50 \pm 17$ & $55 \pm 17$ & $50 \pm 15$ & NS \\
\hline BMI $\left(\mathrm{kg} / \mathrm{m}^{2}\right)$ & $25.0 \pm 5.1$ & $28.4 \pm 6.2$ & $27.6 \pm 5.3$ & $26.9 \pm 7.1$ & NS \\
\hline Alcohol intake (\%) & 25.0 & 12.5 & 24.0 & 33.3 & NS \\
\hline Diabetes & 39.4 & 32.3 & 66.0 & 61.5 & $P<0.01 \mathrm{~b}^{\star} \mathrm{d}^{\star \star} \mathrm{e}^{\star}$ \\
\hline Hepatomegaly (\%) & 46.9 & 15.6 & 14.3 & 35.9 & $P<0.01 \mathrm{a}^{\star \star} \mathrm{b}^{\star \star} \mathrm{f}^{\star}$ \\
\hline Cardiopathy (\%) & 9.4 & 12.5 & 12 & 5.1 & NS \\
\hline Arthralgia (\%) & 34.4 & 0 & 4 & 7.7 & $P<0.001 \mathrm{a}^{\star \star \star} \mathrm{b}^{\star \star \star} \mathrm{c}^{\star \star}$ \\
\hline Melanodermy (\%) & 28.1 & 3.1 & 8 & 7.1 & $P<0.01 \mathrm{a}^{\star \star} \mathrm{b}^{\star} \mathrm{c}^{\star}$ \\
\hline $\begin{array}{l}\text { Increased liver } \\
\text { enzymes (\%) }\end{array}$ & 48.5 & 44.1 & 64 & 64.1 & NS \\
\hline $\begin{array}{l}\text { Serum iron levels } \\
(\mu \mathrm{g} / \mathrm{dl})\end{array}$ & $186.8 \pm 54.2$ & $128.2 \pm 51.5$ & $135.7 \pm 48.5$ & $137 \pm 459.9$ & $P<0.001 \mathrm{a}^{\star * \star} \mathrm{b}^{\star \star *} \mathrm{c}^{\star *}$ \\
\hline $\begin{array}{l}\text { Transferrin } \\
\text { Saturation (\%) }\end{array}$ & $84.9 \pm 30.7$ & $44.5 \pm 18.4$ & $53.2 \pm 21.1$ & $52.7 \pm 25.5$ & $P<0.001 \mathrm{a}^{\star \star \star} \mathrm{b}^{\star \star \star} \mathrm{c}^{\star \star \star}$ \\
\hline Ferritin $(\mu \mathrm{g} / \mathrm{dl})$ & $1577 \pm 2115$ & $557 \pm 947$ & $779 \pm 580$ & $799 \pm 1145$ & $P<0.001 \mathrm{a}^{*} \mathrm{~b}^{*}$ \\
\hline
\end{tabular}

ANOVA test was used to compare means between the four groups, and Wilcoxon test, to compare subgroups two by two. $\chi^{2}$ was used to compare frequencies between the groups. ${ }^{\star} P<0.05 ;{ }^{* \star} P<0.01 ;{ }^{\star \star \star} P<0.001$. Comparison of a: (C282Y homozygosity) and (C282Y heterozygosity), b: $(C 282 Y$ homozygosity) and (composite, H63D homo- or heterozygosity), c: (C282Y homozygosity) and (absence of mutation), d: (C282Y heterozygosity) and (composite H63D homo- or heterozygosity), e: (C282Y heterozygosity) and (no mutation), f: (composite, H63D homo- or heterozygosity) and (no mutation) subgroups.

heterozygosity than the ND group. Our D group (mainly type 2 diabetes) may have exhibited abnormal iron parameters due to insulin resistance, and not to iron overload mediated by a higher frequency of HFE C282Y mutation (5). The fact that the prevalence of the H63D allele was higher in the D group than in the ND group ( $22 \%$ vs $11 \%$ ), but not in the C group (22\% vs $18.3 \%)$ remains unexplained. The frequent $63 \mathrm{D}$ allele was mainly heterozygous in the D group. Such a finding has already been reported with a mild OR of 1.2 for homo(9) but also heterozygous $63 \mathrm{D}$ in a series of $\mathrm{C} 282 \mathrm{Y}$ nonhomozygous patients with physiopathologically proven hepatic iron overload associated with an insulin resistance syndrome (30\% vs $17 \%$ of H63D genotype disturbances in the general population) (10). However, the prevalence of H63D genotype being high in the general population, these results have to be taken with caution even if, for unclear reasons, the frequency of the $63 \mathrm{D}$ allele seems higher in patients with diabetes and/or insulin resistance, according to different studies.

The third aim of this study was to determine the phenotype-genotype correlation of our population of patients with abnormal iron markers. The comparison of phenotypes in D and ND groups showed a higher mean BMI, age, and serum ferritin concentration, as well as a higher ratio of males with increased liver enzymes in the D group. Note that the proportion of excessive drinkers did not differ between the two groups. Table 3 shows that the higher the ferritin level, the higher the frequency of diabetes (despite similar BMI), the proportion of males, and the prevalence of $C 282 \mathrm{Y}$ homozygosity and curiously H63D heterozygosity. These results are concordant with those of Mendler et al. (10), as stated above. Interestingly, despite the fact that we did not check the presence of liver iron overload in our I patients, we found similar results in terms of phenotype-genotype correlation. This means that blood iron markers, much less invasive to obtain than a liver biopsy, should be checked in etiological investigations of diabetes to identify patients who should undergo genotyping.

The interest of studying iron metabolism in the etiological diagnosis of diabetes is still debated, since results of systematic HFE genotyping in diabetes are controversial. However, most studies on HFE genotyping in diabetes do not take iron status into account. In this study, in terms of yield, once diabetes with abnormal iron markers was identified, $69 \%$ of the patients had an abnormal HFE genotype (mainly H63D heterozygosity corresponding to $40 \%$ of the D group). The ratio was not different from the $79 \%$ found in the ND group, in which nearly $60 \%$ of the patients were at least C282Y heterozygous. Approximately 20\% of patients for whom iron parameters had been measured on account of clinical symptoms - excluding isolated liver burden - were diagnosed with $\mathrm{HH}$. Nevertheless the yield of this screening is a bit less profitable in $\mathrm{D}$ than in ND patients since their iron parameters are probably in part altered by insulin resistance itself. By contrast, only $43 \%$ of the control group had an abnormal HFE genotype, with no case of $\mathrm{HH}$ and the same prevalence of H63D heterozygosity than in the D group. When we compared our data to other genotype analyses according to diabetes status (11-19), we found a much higher frequency of HFE gene mutations $(21 \% \quad \mathrm{C} 282 \mathrm{Y}$ homozygote) in the Lille series. This can be explained by the fact that we did not perform genotyping systematically, but only when iron parameters were disturbed. This finding emphasizes the relevance of investigating iron metabolism in patients identified in 
an endocrinological recruitment to improve the effectiveness of genotyping, and perhaps prevent morbimortality (20-25).

Last, patients in the I genotype subgroups differed significantly. The C282 homozygous genotype was mainly characterized by hepatomegaly, arthralgia and melanodermy. The prevalence of diabetes was similar (about $40 \%$ ) in $\mathrm{C} 282 \mathrm{Y}$ homo- and heterozygous groups, whereas its highest prevalence $(60 \%)$ was found in the 'H63D' and 'no mutation' groups. However, ferritin levels were different in these 4 groups, arguing for other factors involved in insulin resistance expression (iron overload, increased liver enzymes, alcohol, BMI, steatosis, inflammatory syndrome, alcohol intake, etc.).

These results raise the question of the role of the C282Y mutation in diabetes. Some studies suggest that the frequency of HFE mutations is increased in type 2 diabetes, probably in relationship with liver iron overload (11-16). Nevertheless, the Rotterdam study has not found an increase of the frequency of HFE mutation in patients with glucose intolerance or type 2 diabetes by comparison with general population or in case control studies $(9,17,18)$. By contrast, the frequency of iron overload in type 2 diabetes is about $40 \%$. The presence of hyperferritinemia, which is considered to be a marker of iron overload, is linked to the incidence of type 2 diabetes in prospective studies (16) and associated with the presence of metabolic syndrome and insulin resistance $(5,6,11,16,19)$. Therefore, the $282 Y$ mutation does not seem to play a direct role in diabetes genesis, but perhaps an indirect one by modulating the iron supply of the organism. The level of ferritin would be controlled by at least two factors: the HFE genotype and the degree of insulin resistance. It is probably the reason why, despite a higher level of blood ferritin in D group (linked to both insulin resistance and HFE genotype), the frequency of $282 Y$ mutation was higher in ND than D group, allowing an increased level of ferritin despite the lack of insulin resistance.

In conclusion, knowledge and strategies in iron overload are a work in progress. Thanks to genotyping, hemochromatosis can now be diagnosed earlier, decreasing the occurrence of complications. The recent national French recommendations for iron overload (ANAES 2004) help achieve early identification of a propositus based on clinical symptoms, followed by iron markers assessment, then genotyping and family inquiry. This study emphasizes the fact that assessment of iron markers is of interest in patients with metabolic disturbances, their HFE genotype being significantly different from a control group with an increased frequency of mutated major allele $282 Y$. Moreover, the genotype differed according to the phenotype with a lower frequency of $\mathrm{C} 282 \mathrm{Y}$ and a higher frequency of H63D heterozygosity in the D group. The phenotypic comparison of $\mathrm{D}$ and $\mathrm{ND}$ groups also showed a higher mean BMI, age, and serum ferritin concentration, as well as an increased proportion of males with increased liver enzymes in the D group. This means that blood iron markers, much less invasive to obtain than liver biopsy, could be checked in etiological investigations of diabetes to identify patients who should undergo genotyping.

\section{References}

1 Pietrangelo A. Hereditary hemochromatosis - a new look at an old disease. New England Journal of Medicine 2004350 2383-2397.

2 Beutler E, Felitti VJ, Koziol JA, Ho NJ \& Gelbart T. Penetrance of 845G - A (C282Y) HFE hereditary haemochromatosis mutation in the USA. Lancet $2002359211-218$.

3 McCune CA, Al-Jader LN, May A, Hayes SL, Jackson HA \& Worwood M. Hereditary haemochromatosis: only $1 \%$ of adult HFE C282Y homozygotes in South Wales have a clinical diagnosis of iron overload. Human Genetics 2002111 538-543.

4 Olynyk JK, Cullen DJ, Aquilia S, Rossi E, Summerville L \& Powell LW. A population-based study of the clinical expression of the hemochromatosis gene. New England Journal of Medicine 1999 $341718-724$.

5 Jehn M, Clark JM \& Guallar E. Serum ferritin and risk of the metabolic syndrome in US adults. Diabetes Care 200427 2422-2428.

6 Woolf B. On estimating the relation between blood group and disease. American Journal of Human Genetics 195519 251-253.

7 Haldane JBS. The estimation and significance of the logarithm of a ratio of frequencies. American Journal of Human Genetics 195620 309-311.

8 Adams PC, Reboussin DM, Barton JC, Mc Laren CE, Eecfeldt JH, Mc Laren GD, Dawkins FW, Acton RT, Harris EL, Gordeuk VR, Leiendecker-Foster C, Speechley M, Snively BM, Holup JL, Thomson E \& Sholinsky P for the Hemochromatosis and Iron overload (HEIRS) Study Research Investigators. Hemochromatosis and iron-overload screening in racially diverse population. New England Journal of Medicine 2005352 1769-1778.

9 Njajou OT, Alizadeh BZ, Vaessen N, Vergeer J, HouwingDuistermaat J, Hofman A, Pols HA \& Van Duijn CM. The role of hemochromatosis $\mathrm{C} 282 \mathrm{Y}$ and $\mathrm{H63D}$ gene mutations in type 2 diabetes: findings from the Rotterdam Study and meta-analysis. Diabetes Care 200225 2112-2113.

10 Mendler MH, Turlin B, Moirand R, Jouanolle AM, Sapey T, Guyader D, Le Gall JY, Brissot P, David V \& Deugnier Y. Insulin resistance-associated hepatic iron overload. Gastroenterology 1999 $1171155-1163$.

11 Tuomainen TP, Nyyssonen K, Salonen R, Tervahauta A, Korpela H, Lakka T, Kaplan GA \& Salonen JT. Body iron stores are associated with serum insulin and blood glucose concentrations. Population study in 1013 eastern Finnish men. Diabetes Care 199720 $426-428$.

12 Dubois-Laforgue D, Larger E \& Timsit J. Is diabetes mellitus a sufficient condition to suspect hemochromatosis? Diabetes and Metabolism 200026 318-321.

13 Van Lerberghe S, Hermans MP, Dahan K \& Buysschaert M. Clinical expression and insulin sensitivity in type 2 diabetic patients with heterozygous mutations for haemochromatosis. Diabetes and Metabolism 200228 33-38.

14 Salonen JT, Tuomainen TP \& Kontula K. Role of C282Y mutation in haemochromatosis gene in development of type 2 diabetes in healthy men: prospective cohort study. British Medical Journal 2000320 1706-1707.

15 Moczulski DK, Grzeszczak W \& Gawlik B. Role of hemochromatosis C282Y and H63D mutations in HFE gene in development of type 2 diabetes and diabetic nephropathy. Diabetes Care 200124 1187-1191.

16 Jiang R, Manson JE, Meigs JB, Ma J, Rifai N \& Hu FB. Body, iron stores in relation to risk of type 2 diabetes in apparently healthy women. Journal of the American Medical Association 2004291 711-717. 
17 Halsall DJ, McFarlane I, Luan J, Cox TM \& Wareham NJ. Typical type 2 diabetes mellitus and HFE gene mutations: a populationbased case-control study. Human Molecular Genetics 200312 1361-1365.

18 Sampson MJ, Williams T, Heyburn PJ, Greenwood RH, Temple RC, Wimperis JZ, Jennings BA \& Willis GA. Prevalence of HFE (hemochromatosis gene) mutations in unselected male patients with type 2 diabetes. Journal of Laboratory and Clinical Medicine $2000135170-173$.

19 Fernandez-Real JM, Lopez-Bermejo A \& Ricart W. Cross-talk between iron metabolism and diabetes. Diabetes $2002 \mathbf{5 1}$ 2348-2354.

20 Hellerbrand C, Poppl A, Hartmann A, Scholmerich J \& Lock G. HFE C282Y heterozygosity in hepatocellular carcinoma: evidence for an increased prevalence. Clinical Gastroenterology and Hepatology $20031279-284$.

21 Mainous AG, 3rd, Gill JM \& Carek PJ. Elevated serum transferrin saturation and mortality. Annals of Family Medicine 20042 133-138.

22 Niederau C, Fischer R, Sonnenberg A, Stremmel W, Trampisch H] \& Strohmeyer G. Survival and causes of death in cirrhotic and in noncirrhotic patients with primary hemochromatosis. New England Journal of Medicine 1985313 1256-1262.
23 Pulliam JF, Jennings CD, Kryscio RJ, Davis DG, Wilson D, Montine TJ, Schmitt FA \& Markesbery WR. Association of HFE mutations with neurodegeneration and oxidative stress in Alzheimer's disease and correlation with ApoE. American Journal of Medical Genetics 2003 119B 48-53.

24 Rubio JP, Bahlo M, Tubridy N, Stankovich J, Burfoot R, Butzkueven H, Chapman C, Johnson L, Marriott M, Mraz G, Tait B, Wilkinson C, Taylor B, Speed TP, Foote SJ \& Kilpatrick TJ. Extended haplotype analysis in the HLA complex reveals an increased frequency of the HFE-C282Y mutation in individuals with multiple sclerosis. Human Genetics 2004114 573-580.

25 Guillygomarc'h A, Mendler MH, Moirand R, Laine F, Quentin V, David V, Brissot P \& Deugnier Y. Venesection therapy of insulin resistance-associated hepatic iron overload. Journal of Hepatology $200135344-349$.

Received 23 October 2005

Accepted 1 March 2006 